\title{
Report of an ESC-EAPCI Task Force on the evaluation and use of bioresorbable scaffolds for percutaneous coronary intervention: executive summary
}

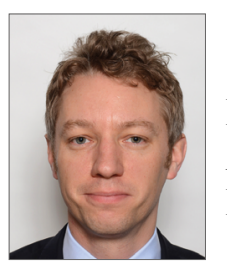

Robert A. Byrne ${ }^{1,2}$, Giulio G. Stefanini ${ }^{3}$, Davide Capodanno ${ }^{4}$, Yoshinobu Onuma 5 , Andreas Baumbach ${ }^{6}$, Javier Escaned 7 , Michael Haude ${ }^{8}$, Stefan James ${ }^{9}$, Michael Joner ${ }^{1,2}$, Peter Jüni ${ }^{10}$, Adnan Kastrati ${ }^{1,2}$, Semih Oktay ${ }^{11}$, William Wijns ${ }^{12,13}$, Patrick W. Serruys ${ }^{14,15}$, Stephan Windecker ${ }^{16 *}$

1. Deutsches Herzzentrum München, Technische Universität München, Germany; 2. DZHK (German Centre for Cardiovascular Research), Partner Site Munich Heart Alliance, Munich, Germany; 3. Division of Cardiology, Cardio Center, Humanitas Research Hospital, Rozzano, Milan, Italy; 4. Cardio-Thoracic-Vascular Department, Ferrarotto Hospital, University of Catania, Italy; 5. Department of Interventional Cardiology Erasmus Medical Center Rotterdam, The Netherlands; 6. Department of Cardiology, St Bartholomew's Hospital, William Harvey Research Institute, and Queen Mary University of London, London, UK; 7. Interventional Cardiology, Hospital San Carlos, Madrid, Spain; 8. Medical Clinic I, Stâdtische Kliniken Neuss, Lukaskrankenhaus GmbH, Neuss, Germany; 9. Clinical Research Center, Uppsala University, Uppsala, Sweden; 10. Applied Health Research Centre, Li Ka Shing Knowledge Institute of St Michael's Hospital, University of Toronto, Toronto, Ontario, Canada; 11. Cardio Med Device Consultants, Baltimore, USA; 12. Saolta University Healthcare Group, Galway, Ireland; 13. The Lambe Institute for Translational Medicine and Curam, National University of Ireland, Galway, Ireland; 14. Erasmus University, Rotterdam, the Netherlands; 15. International Centre for Circulatory Health, National Heart and Lung Institute, Imperial College London, London, UK; 16. Cardiovascular Center Bern, Bern University Hospital, Bern, Switzerland

This paper also includes supplementary data published online at: http://www.pcronline.com/eurointervention/128th_issue/253

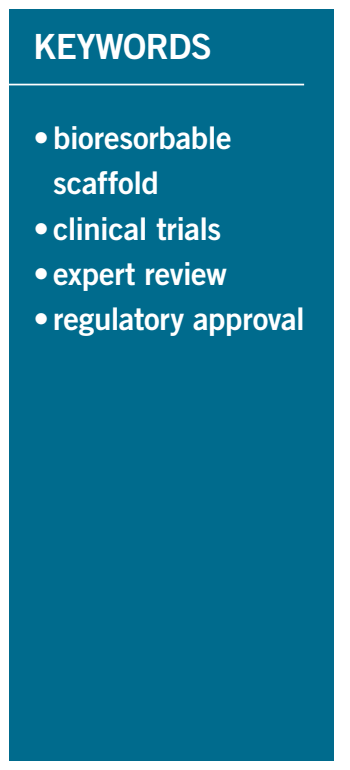

\begin{abstract}
A previous Task Force of the European Society of Cardiology (ESC) and European Association of Percutaneous Cardiovascular Interventions (EAPCI) provided a report on recommendations for the nonclinical and clinical evaluation of coronary stents. Following dialogue with the European Commission, the Task Force was asked to prepare an additional report on the class of devices known as bioresorbable scaffolds (BRS). Five BRS have CE-mark approval for use in Europe. Only one device - the Absorb bioresorbable vascular scaffold - has published randomized clinical trial data and this data show inferior outcomes to conventional drug-eluting stents (DES) at 2-3 years. For this reason, at present BRS should not be preferred to conventional DES in clinical practice. The Task Force recommends that new BRS devices should undergo systematic non-clinical testing according to standardized criteria prior to evaluation in clinical studies. A clinical evaluation plan should include data from a medium sized, randomized trial against DES powered for a surrogate end point of clinical efficacy. Manufacturers of successful devices receive CE- mark approval for use and must have an approved plan for a large-scale randomized clinical trial with planned long-term follow-up.
\end{abstract}

\footnotetext{
*Corresponding author: Tel: +41316324497,Fax: +41316324771.E-mail: stephan.windecker@insel.ch

The article has been co-published with permission in the European Heart Journal [DOI: 10.1093/eurheartj/ehx488] and EuroIntervention [DOI 10.4244/EIJ20170912-01]. All rights reserved in respect of European Heart Journal, (C) The Author 2017, and in respect of EuroIntervention (c) The Author 2017.
} 


\section{Background}

The European Union (EU) medical device advisory document on the evaluation of coronary stents (MEDDEV 2.7.1., Appendix 1) provides guidance, which aims to ensure uniform application of evaluation standards across Europe. At the request of the Clinical Investigation and Evaluation (CIE) Working Group of the Medical Device Experts Group (MDEG, standing committee) of the European Commission, a Task Force the European Society of Cardiology (ESC) and European Association of Percutaneous Cardiovascular Interventions (EAPCI) provided a report containing recommendations for a revision of this document in 2014.

The ESC-EAPCI Task Force presented its report to the European Commission in July 2014 and an executive summary of this report was published in 2015. ${ }^{1}$ Following dialogue between the Joint Research Centre (JRC) - the scientific advisory service of the European Commission - and the Task Force in 2016, the Task Force was asked to prepare an additional report on the class of devices known as bioresorbable scaffolds (BRS). This current report and the previous one will now together provide the evidence that will be used by a task force of regulators drawn from the national competent authorities in Europe as the basis for their redrafting of EU guidance to manufacturers and notified bodies on the preclinical and clinical evaluation of coronary stents. Decision making within this Task Force was based on unanimity for explicit recommendations. There follows an executive summary of the report of this Task Force. It includes recommendations concerning the clinical use of BRS, as well as recommendations for preclinical and clinical evaluation before approval of these devices. The complete text of the report is available online as Supplementary material to the current paper.

Editorial, see page 1506

\section{Introduction and nomenclature}

Bioresorbable scaffolds are also known as bioresorbable stents or fully bioresorbable stents though use of the term BRS is now more widespread and will be preferred in this report. These devices provide temporary mechanical scaffolding in the initial months and years after implantation and subsequently undergo bioresorption. Bioresorbable scaffolds may be classified according to composition of the backbone as either polymeric (pBRS, comprised of polylactic acid or related compounds) or metallic (mBRS, comprised of magnesium alloy). Bioresorbable scaffolds that are drug eluting also include a drug- polymer matrix coating typically consisting of a biodegradable polymer matrix and an antiproliferative drug. The bioresorption process of BRS is often initiated by hydrolysis and results in complete degradation of the backbone skeleton into carbon dioxide and water, amorphous calcium phosphate, and other degradation products depending on the specific platform.

In general terms, bioabsorption is used to reflect the disappearance of the compound of interest and transformation into another substance, ${ }^{2}$ whereas bioresorption indicates the total elimination of the compound by dissolution, assimilation, and excretion., Degradation is used in the case of unknown or ex vivo mechanisms, whereas biodegradation refers to a cell-mediated in vivo mechanism. ${ }^{3}$ Structural fragmentation, disintegration, or dismantling are used to describe physical degradation of polymeric device without systematic breakdown of constituting macromolecules.

\section{Clinical context and potential benefits}

Current generation drug-eluting stents (DES) are a mature technology and the benchmark for new technologies such as BRS. Patients treated with DES demonstrate excellent clinical outcomes at 1 year in both randomized clinical trials and large-scale clinical registries. ${ }^{1,5,6}$ Moreover, although some attrition of performance is observed with clinical follow-up out to 3-5 years, ${ }^{7,8}$ the attrition rates beyond 5 years may be lower, ${ }^{9}$ and the overall medium-term efficacy of this technology is high. In many respects, although unmet need can be said to exist with regard to late adverse events after conventional DES implantation, the overall prognosis of stented patients is good and continues to be determined in large part by events resulting from generalized progression of atherosclerotic disease. ${ }^{10}$ For this reason, the incremental benefit of any new technology should be tangible and clear before it is preferred to DES in routine clinical practice.

A rationale exists for the development of BRS technology and all other things being equal a scaffold that disappears after its useful function in preventing recoil and constrictive remodelling is served is likely to be preferable to a conventional stent. Indeed it is hypothesized that BRS might address late stent failure and potentially eliminate the risk of late adverse stent-related events. In addition, restoration of physiological vasomotion within the treated coronary segment is a potential benefit. This was documented using physiological testing during angiographic surveillance procedures after BRS implantation. ${ }^{11,12}$ However, the ABSORB II trial failed to show improvements in vasomotion within the stented segment with the Absorb pBRS as compared to metallic everolimus-eluting stents (EES) at 3 years. ${ }^{13}$ Other inadequacies of conventional DES that may be addressed by BRS include facilitation of non-invasive surveillance imaging with computed tomography and anastomosis of bypass grafts to treated segments should the need arise, as well as removal of the consequences of permanent jailing of side branches.

\section{Currently approved bioresorbable scaffolds devices in Europe}

An overview of BRS that have received CE mark approval for use in Europe is shown in Table 1. Four polymeric and one metallic BRS have received CE approval as of April 2017: the Absorb bioresorbable vascular scaffold 1.1 (Abbott Vascular, Santa Clara, CA, USA), the DESolve scaffold (Elixir Medical, Sunnyvale, California), the Arterial Remodelling Technologies (ART) pBRS, the Fantom scaffold (Reva Medical, San Diego, CA, USA) as well as the mBRS Magmaris (Biotronik, Berlin, Germany). The Absorb pBRS is also approved for use in the USA and Japan. Key features of the CE mark-approved devices are summarized in Table 1 and principal degradation characteristics of the devices are shown in Figure 1. 
Table 1. Overview of CE-marked bioresorbable scaffolds.

\begin{tabular}{|c|c|c|c|c|c|c|c|c|c|c|c|}
\hline $\begin{array}{c}\text { Commercial } \\
\text { name }\end{array}$ & \begin{tabular}{|c|} 
Manufacturer/ \\
approving \\
notified body
\end{tabular} & $\begin{array}{l}\text { Backbone } \\
\text { material }\end{array}$ & $\begin{array}{l}\text { Coating } \\
\text { material }\end{array}$ & $\begin{array}{c}\text { Device } \\
\text { thickness }\end{array}$ & Drug release & Drug load & $\begin{array}{l}\text { Duration } \\
\text { of drug } \\
\text { release }\end{array}$ & $\begin{array}{l}\text { Bioresorption } \\
\text { in preclinical } \\
\text { swine models }\end{array}$ & $\begin{array}{l}\text { Year of } \\
\text { CE-mark }\end{array}$ & $\begin{array}{c}\text { Year of } \\
\text { FDA } \\
\text { approval }\end{array}$ & $\begin{array}{c}\text { Year of PDMA } \\
\text { (Japan) } \\
\text { approval }\end{array}$ \\
\hline $\begin{array}{l}\text { ABSORB BVS } \\
1.1\end{array}$ & $\begin{array}{c}\text { Abbott Vascular/ } \\
\text { BSI }\end{array}$ & PLLA & PDLLA & $156 \mathrm{~mm}$ & Everolimus & $\begin{array}{l}76-308 \text { lg/ } \\
\text { stent }\end{array}$ & 3 months & 36 months & 2011 & 2016 & 2016 \\
\hline $\begin{array}{l}\text { DESolve } \\
\text { (pDESolve 100/ } \\
\text { DESolve CX/ } \\
\text { DESolve NXT) }\end{array}$ & $\begin{array}{l}\text { Elixir Medical/ } \\
\text { LRQA }\end{array}$ & PLLA & PLLA & $\begin{array}{c}100- \\
150 \mathrm{~mm}\end{array}$ & Novolimus & NA & 3 months & 24 months & 2014 & NA & NA \\
\hline ART Pure & ART/NA & PDLLA & NA & $170 \mathrm{~mm}$ & No drug elution & no drug & NA & 24 months & 2015 & NA & NA \\
\hline Magmaris & Biotronik/BSI & Magnesium alloy & PLLA & $150 \mathrm{~mm}$ & Sirolimus & $1.4 \mathrm{lg} / \mathrm{mm}^{2}$ & 3 months & 9-12 months & 2016 & NA & NA \\
\hline Fantom & Reva/NA & PTD-PC & PTD-PC & $125 \mathrm{~mm}$ & Sirolimus & $115 \mathrm{mg}$ & NA & $<3$ years & 2017 & NA & NA \\
\hline
\end{tabular}

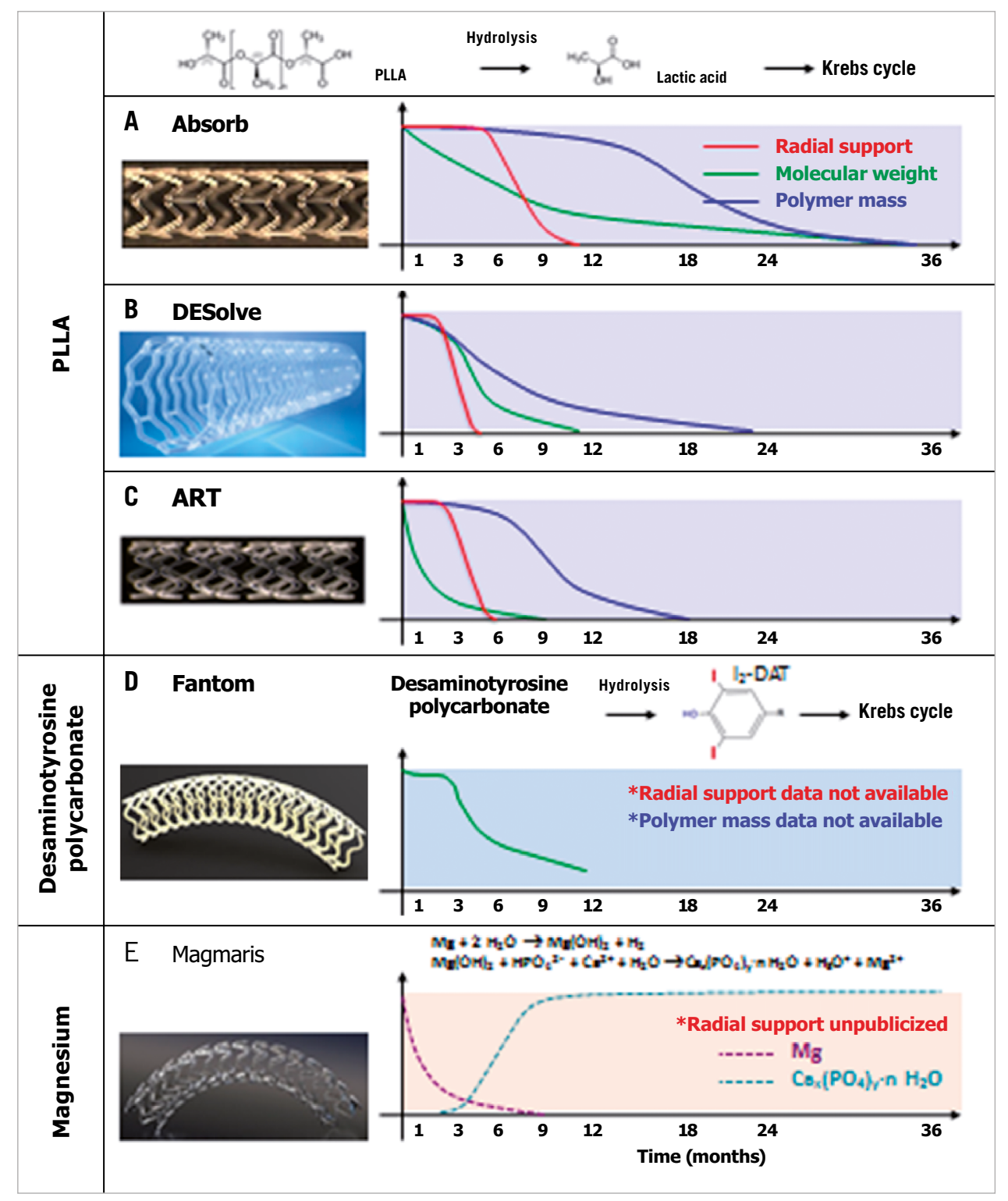

Figure 1. Principal degradation characteristics of CE-marked bioresorbable scaffolds. For each device data are shown, where available, for radial support and molecular weight and mass of the polymer over time. For the magnesium scaffold, the content of magnesium and calcium phosphate (a conversion product) over time is shown. PLLA: poly-L-lactic acid 


\section{Clinical outcomes with CE-approved bioresorbable scaffolds ABSORB BIORESORBABLE SCAFFOLD}

The everolimus-eluting Absorb pBRS received CE mark approval for use in January 2011. It is the only device in this class with clinical outcome data from randomized clinical trials and to have reached limited use in clinical practice to date. Seven randomized clinical trials have investigated outcomes in studies with and without protocol mandated imaging follow-up to date (Table 2). ${ }^{13-19}$ The main clinical outcomes of each of the randomized clinical trials at the time point of latest follow-up are detailed in Table 3. ${ }^{13,19-24}$

The two largest trials were ABSORB-III and AIDA. Enrolling 2008 patients, the ABSORB III trial is the largest randomized trial reported to date. ${ }^{17}$ Patients were randomly assigned in a $2: 1$ ratio (active treatment vs. control) after predilatation of the target lesion. The primary end point was target lesion failure (TLF) and noninferiority was assessed against an expected event rate of $7 \%$ with a pre-specified non-inferiority margin of $4.5 \%$. The main finding of the study was that TLF at 1 year was non-inferior with BRS vs. EES in both intention-to-treat [7.8\% vs. $6.1 \%$, difference $1.7 \%$, upper bound of $95 \%$ confidence interval (CI) $3.9 \%, \mathrm{P}_{\text {non-inferiority }}$ 0.007 ] and as treated analyses $(8.0 \%$ vs. $6.0 \%$, difference $2.0 \%$ upper bound of $\left.95 \% \mathrm{CI} 4.1 \%, \mathrm{P}_{\text {non-inferiority }} 0.01\right)$. Rates of target vessel myocardial infarction (MI) $(6.0 \%$ vs. $4.6 \%$; $\mathrm{P}=0.18)$ and definite/probable stent/scaffold thrombosis at 1 year were numerically higher with BRS ( $1.5 \%$ vs. $0.7 \%, \mathrm{P}=0.13)$. Results of 2 -year follow-up have recently been presented showing a higher rate of TLF (11.0\% vs. $7.9 \%, \mathrm{P}=0.03)$ and target vessel $\mathrm{MI}(7.3 \%$ vs. $4.9 \%$, $\mathrm{P}=0.04)$ with BRS vs. EES as well as a numerically higher rate of stent/scaffold thrombosis with BRS (1.9\% vs. $0.8 \%){ }^{2}$

The AIDA investigator-initiated trial enrolled patients undergoing intervention in routine practice including patients with acute coronary syndromes. ${ }^{19}$ The trial intended to test non-inferiority of BRS vs. EES at 2 years. However, during follow-up and after full enrolment the data and safety monitoring board of the trial recommended early reporting due to safety concerns. At the time of reporting, the median duration of follow-up was 707 days. The primary end point - a composite of cardiac death, target vessel MI, or target vessel revascularization - was similar in both groups [11.7\% vs. $10.7 \%$, hazard ratio 1.12 (0.85-1.48), $\mathrm{P}=0.43$ ]. Definite/ probable stent/scaffold thrombosis was significantly higher in the BRS treatment group ( $3.5 \%$ vs. $0.9 \%, \mathrm{P}<0.001)$.

Meta-analysis of the first six trials with reported follow-up at 1 year shows rates of target lesion revascularization (TLR) with ABSORB BRS that are comparable to metallic EES but a two-fold increase in the risk of stent/scaffold thrombosis (see Figure 2) ${ }^{25}$ A pooled analysis of individual patient data from the four industry-sponsored studies showed broadly concordant findings. ${ }^{26}$ Most of this increased risk occurred inside the first 30 days suggesting an association with the procedural outcomes. In this respect, analysis from two registries suggests that modification of implantation technique might lead to improved clinical outcomes..$^{27,28}$

A meta-analysis of all seven randomised trials reporting longterm follow-up with a minimum 2-year clinical follow-up was recently done. ${ }^{29}$ A total of 5583 included patients received BRS $(n=3261)$ or EES $(n=2322)$. Weighted median follow-up was 26.6 months. Patients treated with BRS vs. EES showed higher risk for TLF [odds ratio, $(\mathrm{OR})(95 \% \mathrm{CI})=1.35(1.14-1.61), \mathrm{P}=0.005$ ] (Figure 3A) due to a higher risk of target vessel MI [OR 1.68 (1.212.33), $\mathrm{P}=0.008$ ] and ischaemia-driven TLR [OR 1.42 (1.14-1.78), $\mathrm{P}=0.008]$. Patients treated with BRS vs. EES showed a higher risk for definite/probable stent/scaffold thrombosis [OR 3.24 (2.344.50), $\mathrm{P}=0.0001$ ] (Figure 3B), most marked in the period beyond 1 year after implantation [OR 4.03 (2.11-7.68); $\mathrm{P}=0.003$ ].

Table 2. Main baseline characteristics of patients in enrolled in randomized trials comparing the absorb bioresorbable scaffolds with conventional metallic drug-eluting stents.

\begin{tabular}{|c|c|c|c|c|c|c|c|c|}
\hline Trials & Patients (n) & Age (years) & Males (\%) & Diabetes (\%) & $\begin{array}{c}\text { ACS at } \\
\text { admission (\%) }\end{array}$ & Lesions (n) & RVD (mm) & Length (mm) \\
\hline ABSORB $\|^{13}$ & 501 & 61.2 & 78 & 24 & $21^{a}$ & 546 & 2.61 & 13.8 \\
\hline ABSORB III ${ }^{17}$ & 2,008 & 63.5 & 70 & 32 & $26^{a}$ & 2,098 & 2.66 & 12.8 \\
\hline ABSORB China ${ }^{16}$ & 480 & 57.4 & 72 & 24 & $64^{a}$ & 503 & 2.81 & 14.0 \\
\hline ABSORB Japan ${ }^{15}$ & 400 & 67.2 & 76 & 36 & $13^{a}$ & 412 & 2.75 & 13.4 \\
\hline AIDA $^{19}$ & 1,845 & 64.2 & 74 & 18 & 54 & 2,446 & 2.67 & 18.9 \\
\hline EVERBIO $\|^{14}$ & 240 & 65.0 & 79 & 19 & 35 & 325 & 2.58 & NA \\
\hline TROFI III8 & 191 & 58.6 & 82 & 17 & 100 & 193 & 2.81 & 13.1 \\
\hline \multicolumn{9}{|c|}{ 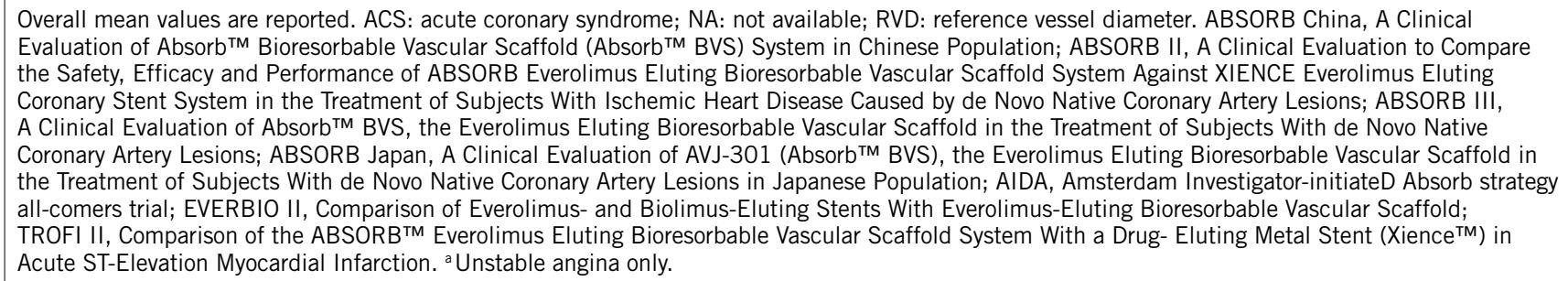 } \\
\hline
\end{tabular}


Table 3. Clinical outcomes at long-term follow-up from seven randomized trials comparing bioresorbable scaffolds vs. metallic everolimus-eluting stents.

\begin{tabular}{|c|c|c|c|c|c|c|c|c|c|}
\hline & TLF & POCE & Death & Cardiac death & MI & TVMI & TLR & $\begin{array}{l}\text { D/P-stent/ } \\
\text { scaffold } \\
\text { thrombosis }\end{array}$ & $\begin{array}{l}\text { Def stent/ } \\
\text { scaffold } \\
\text { thrombosis }\end{array}$ \\
\hline ABSORB $\|^{b} 13$ & $\begin{array}{c}34 / 325(10) \\
\text { vs. } 8 / 161(5)\end{array}$ & $\begin{array}{c}68 / 325(21) \\
\text { vs. } 39 / 161 \text { (24) }\end{array}$ & $\begin{array}{c}8 / 325 \text { (2) } \\
\text { vs. } 6 / 161 \text { (4) }\end{array}$ & $\begin{array}{c}3 / 325(1) \\
\text { vs. } 3 / 161 \text { (2) }\end{array}$ & $\begin{array}{c}27 / 325(8) \\
\text { vs. } 5 / 161(3)\end{array}$ & $\begin{array}{c}23 / 325(7) \\
\text { vs. } 2 / 161(1)\end{array}$ & $\begin{array}{c}20 / 325(6) \\
\text { vs } 3 / 161(2)^{a}\end{array}$ & $\begin{array}{c}\text { 9/320 (3) } \\
\text { vs. 0/159 (0) }\end{array}$ & $\begin{array}{c}8 / 320(3) \\
\text { vs. } 0 / 159(0)\end{array}$ \\
\hline ABSORB III24 & $\begin{array}{l}143 / 1322(11.0) \\
\text { vs. 53/686 (7.9) }\end{array}$ & NA & NA & $\begin{array}{c}14 / 1322(1.1) \\
\text { vs. } 4 / 686(0.6)\end{array}$ & NA & $\begin{array}{c}95 / 1322(7.3) \\
\text { vs. } 33 / 686(4.9)\end{array}$ & $\begin{array}{c}69 / 1322(5.3) \\
\text { vs. } 29 / 686(4.3)\end{array}$ & \begin{tabular}{|l|}
$24 / 1322(1.9)$ \\
vs. $5 / 686(0.8)$
\end{tabular} & NA \\
\hline $\begin{array}{l}\text { ABSORB } \\
\text { China }^{\text {b23 }}\end{array}$ & $\begin{array}{c}13 / 236(5.5) \\
\text { vs. } 11 / 235(4.7)\end{array}$ & $\begin{array}{c}28 / 236(11.9) \\
\text { vs. } 28 / 235(11.9)\end{array}$ & $\begin{array}{c}2 / 236(0.8) \\
\text { vs. } 6 / 235(2.6)\end{array}$ & $\begin{array}{c}1 / 236(0.4) \\
\text { vs. } 3 / 235(0.9)\end{array}$ & $\begin{array}{c}8 / 236(3.4) \\
\text { vs. } 5 / 235(2.1)\end{array}$ & $\begin{array}{c}6 / 236(2.5) \\
\text { vs. } 2 / 235(0.9)\end{array}$ & $\begin{array}{c}10 / 236(4.2) \\
\text { vs. } 6 / 237(2.5)^{\mathrm{a}}\end{array}$ & $\begin{array}{c}2 / 235(0.9) \\
\text { vs. } 0 / 229(0)\end{array}$ & $\begin{array}{c}1 / 235(0.4) \\
\text { vs. } 0 / 229(0)\end{array}$ \\
\hline $\begin{array}{l}\text { ABSORB } \\
\text { Japan } 222\end{array}$ & $\begin{array}{c}23 / 258(8.9) \\
\text { vs. } 7 / 128(5.5)\end{array}$ & NA & NA & $\begin{array}{c}1 / 258(0.4) \\
\text { vs. } 0 / 128(0)\end{array}$ & NA & $\begin{array}{c}14 / 258(5.4) \\
\text { vs. } 4 / 128(3.1)\end{array}$ & $\begin{array}{c}18 / 258(7.0) \\
\text { vs. } 5 / 128(3.9)^{a}\end{array}$ & $\begin{array}{c}\text { 9/258 (3.5) } \\
\text { vs. 2/128 (1.6) }\end{array}$ & NA \\
\hline AIDA $^{19}$ & $\begin{array}{c}\text { 91/924 (10.3) } \\
\text { vs. } 78(8.9)\end{array}$ & $\begin{array}{c}105 / 924(11.7) \\
\text { vs. } 94 / 921(10.7)\end{array}$ & $\begin{array}{c}32 / 924(3.5) \\
\text { vs. } 43 / 921(4.3)\end{array}$ & $\begin{array}{l}18 / 924(2.0) \\
\text { vs. } 23(2.7)\end{array}$ & $\begin{array}{l}62 / 924(7.1) \\
\text { vs. } 41(4.2)\end{array}$ & $\begin{array}{l}48 / 924(5.5) \\
\text { vs. } 30(3.2)\end{array}$ & $\begin{array}{l}60 / 924(7.0) \\
\text { vs. } 45(5.2)\end{array}$ & $\begin{array}{c}31(3.5) \\
\text { vs. } 8(0.9)\end{array}$ & $\begin{array}{c}27(3.1) \\
\text { vs. } 5(0.6)\end{array}$ \\
\hline EVERBI0 ${ }^{20}$ & $\begin{array}{c}16(21) \\
\text { vs. } 13(16)\end{array}$ & $\begin{array}{c}27(35) \\
\text { vs. } 30 \text { (38) }\end{array}$ & $\begin{array}{c}2(3) \\
\text { vs. } 4 \text { (5) }\end{array}$ & $\begin{array}{c}1(1) \\
\text { vs. } 1(1)\end{array}$ & $\begin{array}{c}4(5) \\
\text { vs. } 2 \text { (3) }\end{array}$ & $\begin{array}{c}2(3) \\
\text { vs. } 0(0)\end{array}$ & $\begin{array}{c}11(14) \\
\text { vs. } 8(10)\end{array}$ & $\begin{array}{c}1(1) \\
\text { vs. } 0(0)\end{array}$ & $\begin{array}{c}1(1) \\
\text { vs. } 0(0)\end{array}$ \\
\hline TROFI $\|^{21}$ & $\begin{array}{c}3(3.2) \\
\text { vs. } 3(3.2)\end{array}$ & NA & $\begin{array}{c}1(1.1) \\
\text { vs. } 1(1.0)\end{array}$ & $\begin{array}{c}1(1.1) \\
\text { vs. } 1(1.0)\end{array}$ & $\begin{array}{c}3(3.2) \\
\text { vs. } 3(3.2)\end{array}$ & $\begin{array}{c}2(2.1) \\
\text { vs. } 3(3.2)\end{array}$ & $\begin{array}{c}2(2.1) \\
\text { vs. } 1(1.0)^{\mathrm{a}}\end{array}$ & $\begin{array}{l}\text { 2/95 (2.1) } \\
\text { vs. } 1(1.0)\end{array}$ & $\begin{array}{c}2(2.1) \\
\text { vs. } 1(1.0)\end{array}$ \\
\hline
\end{tabular}

In terms of registry studies, results from a large number of predominantly small and moderate sized clinical registries have been published. The largest reported datasets were consistent in showing generally acceptable clinical outcomes at 1 year. ${ }^{28,30-33}$ Rates of stent/scaffold thrombosis appeared somewhat higher than those observed with conventional DES in routine clinical practice..$^{28,30-33}$ Importantly, it should be noted that despite the implantation of significant numbers of devices worldwide in the years since approval - estimated to be of the order of $>200,000$ devices - only a small proportion of patients have been entered into registries with reports that have been published in the peer-reviewed literature.

Recent data from long-term follow-up of randomized trials provided evidence regarding a possible excess of very late stent/scaffold thrombosis with Absorb pBRS in comparison with conventional

\section{A In-device late lumen loss}

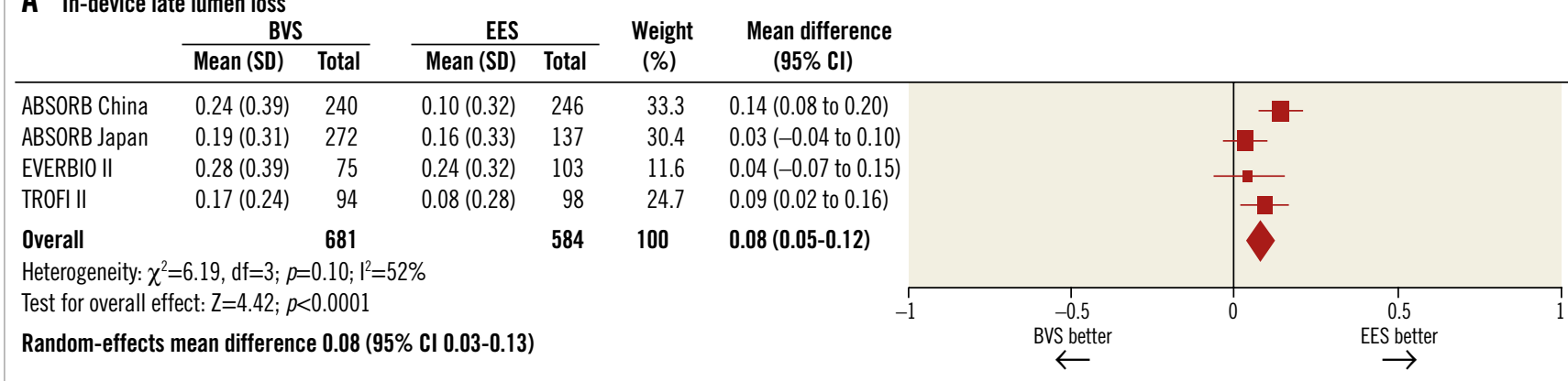

B In-segment late lumen loss

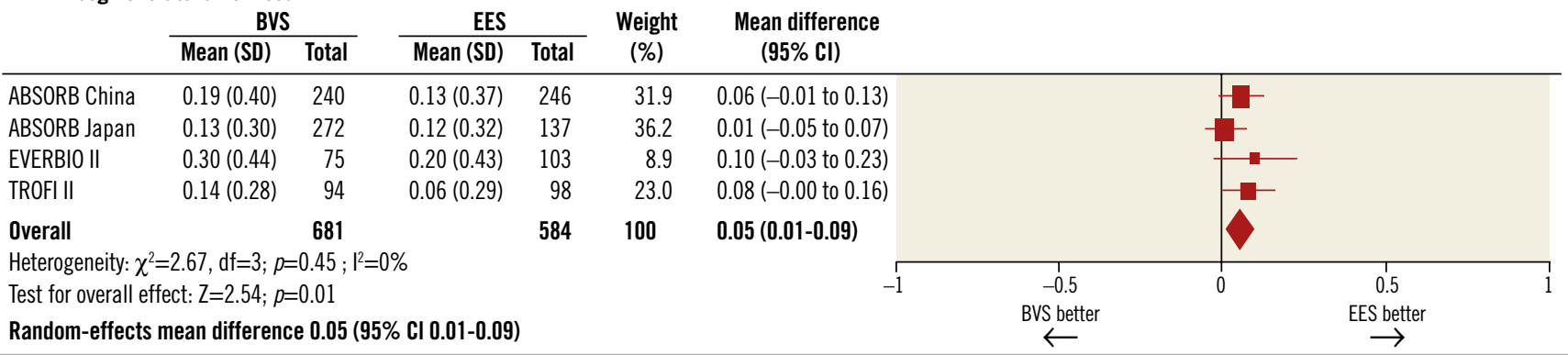

Figure 2. Meta-analysis of differences in late lumen loss between bioresorbable scaffolds and conventional drug-eluting stents in trials with angiographic surveillance scheduled at 6-12 months follow-up. Plots of weighted mean difference in (A) in-device and (B) in-segment late loss. The boxes/diamonds indicate the point estimate and the left and the right ends of the lines the 95\% confidence interval (CI). BVS: Absorb bioresorbable vascular scaffold; EES: everolimus-eluting stent ${ }^{25}$ 


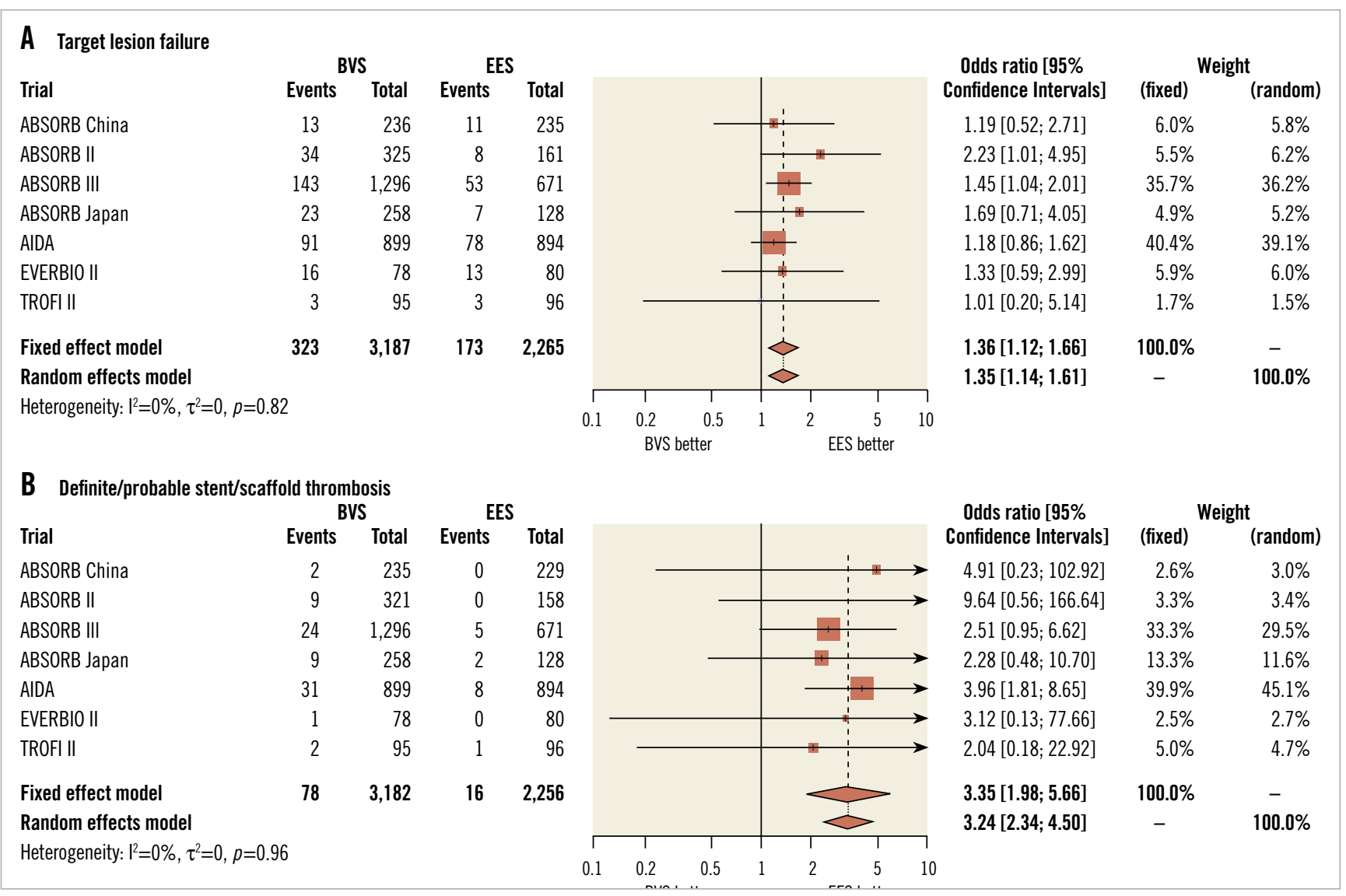

Figure 3. Risk of target lesion failure and stent/scaffold thrombosis at follow-up of 2 years or more in meta-analysis of seven randomized controlled trials comparing bioresorbable scaffolds and conventional drug-eluting stents. (A) target lesion failure; (B) stent/scaffold thrombosis. Odds ratios for target lesion failure with polymeric bioresorbable scaffolds vs. EES. The diamonds indicate the point estimate and the left and the right ends of the lines the [95\% confidence interval, CI]. BVS: bioresorbable stent (i.e. Absorb polymeric bioresorbable scaffolds); EES: everolimus-eluting stent ${ }^{29}$

stents. ${ }^{20,26-31,29}$ Three main factors are hypothesized to be involved in late/very late scaffold thrombosis: (i) alteration in laminar flow as a consequence of loss of integrity of the scaffold backbone; this may lead to prolapse of part of the scaffold into the vessel lumen; (ii) thrombogenicity of the breakdown products and/or the extracellular matrix replacing the strut void; and (iii) effects of inflammation at a tissue level due to breakdown/resorption of the scaffold at a time when protection is now longer provided by drug elution from the scaffold backbone. ${ }^{34-36}$ While in acute and subacute scaffold thrombosis cases, strut malapposition, incomplete lesion coverage and under-deployment were the most frequently observed imaging findings in late and very late scaffold thrombosis cases, malapposition, late discontinuity and peri-strut low intensity area were frequently observed at the time of event. ${ }^{36}$ Among these imaging findings, late discontinuities are specifically related to the BRS technology.

\section{DESolve BIORESORBABLE SCAFFOLD}

The novolimus-eluting DESolve pBRS received $\mathrm{CE}$ mark approval in May 2014. The single arm DESolve Nx trial enrolled 126 patients treated with $150 \mathrm{~lm}$ thickness pBRS. At 2 years major adverse cardiac events were observed in $7.4 \% .{ }^{37}$ No randomized clinical trial data are available to date.

A single comparative analysis between the DESolve BRS and the Absorb BRS is available using a propensity-score matching model. ${ }^{38}$ The main finding was that outcomes at 1 year were similar between the two devices: the 1-year rates of TLF ( 4.7 vs. $4.5 \%$; $\mathrm{P}=0.851$ ), TLR (2.6 vs. $3.5 \% ; \mathrm{P}=0.768)$, cardiac death ( 1.5 vs. $2.0 \% ; \mathrm{P}=0.752$ ), and definite stent/scaffold thrombosis (2.0 vs. $1.0 \% ; \mathrm{P}=0.529) \mathrm{did}$ not differ significantly between Absorb BRS and DESolve BRS.

\section{MAGMARIS BIORESORBABLE MAGNESIUM SCAFFOLD}

The Magmaris drug-eluting mBRS received CE mark approval in June 2016. Clinical data are limited to results from the BIOSOLVE-II study, a single arm study enrolling 123 patients..$^{39,40}$ Overall rates of clinical events at 12 months were low: TLF was observed in $3.4 \%$, 95\% CI: 0.9-8.4. No randomized clinical trial data are available to date.

\section{ART BIORESORBABLE SCAFFOLD}

This is a non-drug eluting pBRS. There are no published clinical outcome data with this device. 


\section{FANTOM BIORESORBABLE SCAFFOLD}

This is a drug-eluting pBRS with a radio-opaque platform (in contradistinction to the other approved scaffolds). There are no published clinical outcome data with this device.

\section{Angiographic outcomes with CE-approved bioresorbable scaffolds ABSORB BIORESORBABLE SCAFFOLD}

A number of randomized trials compared outcomes of patients treated with Absorb BRS with conventional metallic DES, and incorporated protocol-mandated angiographic follow-up.

- In the ABSORB China trial, the primary end point of insegment late loss at 1 year was $0.19 \pm 0.38 \mathrm{~mm}$ for BRS vs. $0.13 \pm 0.38 \mathrm{~mm}$ for EES (one- sided $97.5 \%$ upper confidence limit of the difference $\left.=0.14 \mathrm{~mm}, \mathrm{P}_{\text {non-inferiority }}=0.01\right){ }^{16}$

- In ABSORB-Japan in-segment late loss at 13 months was $0.13 \pm 0.30 \mathrm{~mm}$ with BRS and $0.12 \pm 0.32 \mathrm{~mm}$ with EES (upper one-sided 95 confidence limit of the difference $=0.07$ ); $\left.\mathrm{P}_{\text {non-inferiority }}<0.0001\right) .{ }^{15,34}$

- Data from the EVERBIO-II trial showed that in-stent late loss at 9 months was similar between patients treated with BRS $(0.28 \pm 0.39 \mathrm{~mm})$ and with EES/biolimus A9-eluting stent $(0.25 \pm 0.36 \mathrm{~mm}, \mathrm{P}=0.30) .{ }^{14}$

- In the TROFI II trial in-stent late loss at 6 months favoured conventional stents (Absorb BRS: $0.17 \pm 0.24 \mathrm{~mm}$ vs. EES: $0.08 \pm 0.28 \mathrm{~mm}, \mathrm{P}=0.024){ }^{18}$

- In the ABSORB II trial, the 3-year co-primary end points were vasomotor reactivity (powered for superiority) and late lumen loss (powered for non-inferiority). The trial failed to show superiority with respect to vasomotor reactivity at 3 years [Absorb BRS $0.047 \mathrm{~mm}$ standard deviation (SD) (0.109) vs. EES $0.056 \mathrm{~mm}(0.117)$; P-superiority=0.49] as well as non-inferiority for the co-primary end point of late lumen loss that was larger with Absorb BRS than EES (0.37 mm [0.45] vs. $0.25 \mathrm{~mm}$ $\left.[0.25] ; P_{\text {non-inferiority }}=0.78\right)$. Minimum lumen diameter at 3 years was $1.86 \mathrm{~mm}$ (SD 0.54) in the Absorb group vs. $2.25 \mathrm{~mm}(0.37)$ in the Xience group $(\mathrm{P}<0.0001)$.

Meta-analysis of the four trials with angiographic surveillance scheduled in the time window that is usual for the assessment of conventional metallic DES shows that both in-device and in-segment late loss are significantly higher for the Absorb BRS compared with metallic EES. ${ }^{25}$

In terms of registry data from routine practice with angiographic follow-up, device performance was broadly in line with clinical trial data with respect to angiographic antirestenotic efficacy. The ISAR-ABSORB registry showed a mean in-stent late loss of $0.26 \pm 0.51$ in 286 patients undergoing surveillance angiography at a median of 196 days after stenting. ${ }^{33}$

\section{DESolve BIORESORBABLE SCAFFOLD}

In the DESolve Nx trial at 6-month angiographic follow-up, the novolimus-eluting bioresorbable DESolve scaffold showed instent late lumen loss of $0.20 \pm 0.32 \mathrm{~mm} \cdot{ }^{37}$

\section{MAGMARIS BIORESORBABLE SCAFFOLD}

In the BIOSOLVE-II trial, mean late lumen loss at follow-up with the drug-eluting Magmaris mBRS was somewhat higher than is seen with conventional metallic DES and remained stable between 6 and 12 months: in-segment late lumen loss $0.20 \pm 0.21 \mathrm{~mm}$ and $0.25 \pm 0.22 \mathrm{~mm}, \mathrm{P}=0.117$, delta late loss $0.05 \pm 0.21 \mathrm{~mm}(95 \%$ CI: $20.01 ; 0.12)$; in-scaffold late lumen loss $0.37 \pm 0.25 \mathrm{~mm}$ vs. $0.39 \pm 0.27 \mathrm{~mm}, \mathrm{P}=0.446$, delta late loss $0.03 \pm 0.22$ (95\% CI: 20.04 $0.10)$, respectively. ${ }^{39,40}$

\section{OTHER SCAFFOLDS}

Published angiographic surveillance data are not available with the ART and Fantom scaffolds.

\section{Recommendations for dual antiplatelet therapy in patients treated with bioresorbable scaffolds}

Treatment with dual antiplatelet therapy (DAPT) with aspirin and a $\mathrm{P}_{12} \mathrm{Y}_{12}$ inhibitor after BRS implantation is mandatory to mitigate the risk of scaffold thrombosis. Yet, the optimal duration of such DAPT treatment is unknown. The ESC clinical practice guidelines on myocardial revascularization recommend DAPT for a minimum of 6 months after new generation metallic DES implantation, but no specific recommendations are made for BRS. ${ }^{41}$

In considering DAPT regime after BRS a number of aspects have to be considered. Thicker and wider BRS stent struts might confer a higher risk of stent thrombosis in comparison to thinstrut conventional DES. Moreover, thicker stent struts may take longer to completely endothelialize. Importantly, due to concerns regarding scaffold thrombosis late in the course of scaffold degradation at 2-3 years, it is conceivable that the duration of DAPT treatment may need to be prolonged to the time of BRS bioresorption.

At 3-year follow-up of the ABSORB II trial, nine patients presented with scaffold thrombosis; six of these cases (78\%) presented with late or very late scaffold thrombosis. ${ }^{13}$ In all of them, scaffold thrombosis had occurred after discontinuation of DAPT, in most cases after a long period of antiplatelet monotherapy: in eight patients (87\%) scaffold thrombosis occurred more than 100 days after DAPT was discontinued. Of note, there were no cases of late/very late scaffold thrombosis in the 63 patients in the scaffold arm in whom DAPT was maintained without interruption for 3 years. In a meta-analysis examining late outcomes of patients treated with pBRS, of 12 patients presenting with very late scaffold thrombosis only 1 patient was on DAPT. ${ }^{42}$ In addition, a recent report of data pooled from three registries suggested that in patients event-free at 6 months, the incidence of scaffold thrombosis was low while on DAPT but higher when DAPT was terminated before 18 months. ${ }^{43}$

Overall, available data suggest that current BRS may require prolonged DAPT to mitigate the risk of late and very late scaffold thrombosis. It is unknown whether use of more potent $\mathrm{P} 2 \mathrm{Y}_{12}$ inhibitors, such as ticagrelor or prasugrel, may have a more protective effect against scaffold thrombosis than DAPT with clopidogrel. 
As prolonged DAPT confers a higher risk of bleeding events, prolonged DAPT duration will impact net clinical benefit.

Patients who cannot tolerate or are unlikely to be compliant with extended duration DAPT are not candidates for BRS treatment. Patients with an indication for oral anticoagulation are not candidates for BRS at this point in time.

In patients who have already been treated with BRS, there are two scenarios to be considered. In patients who remain on DAPT without clinical events, it is recommended to continue DAPT for the duration of bioresorption expected on the basis of existing non-clinical and clinical studies (e.g. at least 36 months in case of the Absorb pBRS). In patients who have discontinued DAPT prior to this time point, a decision to re-initiate DAPT should be made on a caseby-case basis after evaluation of the thrombotic and bleeding risks.

\section{Recommendations for use of bioresorbable scaffolds in clinical studies}

There are sufficient clinical data to inform recommendations of this Task Force only about the everolimus-eluting Absorb pBRS. For the other devices, there are insufficient data to inform recommendations. These scaffolds may be used according to ongoing clinical investigations and their outcomes. Of note, data regarding cost-effectiveness do not exist and may differ widely according to each local health care system and reimbursement scheme.

Current data from randomized trials and meta-analyses compare the everolimus-eluting Absorb pBRS with the metallic EES in patients with predominantly stable coronary artery disease, and with simple to moderately complex lesion characteristics. They suggest similar clinical efficacy at one year, as it relates to the risk of TLR and to the device-oriented composite outcome TLF. However, the risks of target-vessel MI and definite or probable stent/scaffold thrombosis are increased in patients treated with the Absorb BRS. Moreover, late outcomes out to 2-3 years suggest an excess of very late stent/scaffold thrombosis, target vessel MI, and TLF, with BRS vs. metallic EES. Current evidence suggests no late advantage in terms of clinical efficacy including relief of angina pectoris. Thus the Task Force has the following recommendations for the clinical use of BRS as an alternative to conventional metallic DES:

\section{GENERAL RECOMMENDATIONS FOR CLINICAL USE OF APPROVED DEVICES}

- As long as concerns regarding long-term clinical safety (i.e. MI, stent/scaffold thrombosis) have not been dispelled by on-going clinical trials or prospective, monitored registries, BRS should not be preferred to current generation metallic DES for clinical use in daily practice.

- On-going trials should be closely monitored for adverse events and data should be made available at regular intervals in the public domain, irrespective of the initial analysis plan.

- It is not recommended to use BRS in patients who cannot tolerate or are unlikely to be compliant with extended duration DAPT or who require oral anticoagulants.

\section{PROCEDURAL RECOMMENDATIONS FOR USE OF APPROVED DEVICES}

Although implantation technique has progressively evolved with time, at present there is no evidence from prospectively conducted trials that specific procedural techniques can impact on clinical outcomes. Accordingly, the following recommendations are based on the opinion of the Task Force members.

\section{i. LESION ASSESSMENT}

BRS require careful lesion assessment, to determine the need and extent of lesion preparation, as well as to select the appropriate size and length of the device. The use of pre-and post-procedural intracoronary imaging (Intravascular ultrasound, optical coherence tomography), as well as online quantitative coronary angiography, is encouraged to optimize device implantation. The use of BRS in heavily calcified vessels is strongly discouraged. Bioresorbable scaffolds should be avoided in stenoses with reference diameter smaller than $2.5 \mathrm{~mm}$ and in ostial lesions.

\section{ii. DEVICE IMPLANTATION}

Consistent observations point to the differences in mechanical properties of BRS compared with metallic DES. This mandates meticulous assessment and preparation of the lesion, and also frequent use of pre- and post-dilatation. As a result, procedure duration and contrast use are increased. Moreover, acute performance, as assessed by acute gain and percent diameter stenosis are inferior for BRS as compared with metallic DES. As a result, it is recommended that BRS are implanted by appropriately trained operators with specific experience in the implantation of these devices.

\section{iii. PRE-DILATION}

It is recommended to systematically predilate lesions with noncompliant balloons, aiming at a balloon diameter corresponding to the estimated reference vessel diameter.

- Complete balloon expansion should be ensured, in orthogonal angiographic projections.

- In case of incomplete balloon expansion during pre-dilation, use of plaque modification techniques (cutting/scoring balloon, rotational atherectomy) should be considered prior to BRS insertion.

- It is recommended to refrain from BRS implantation in cases where balloon expansion remains incomplete despite plaque modification techniques.

iv. IMPLANTATION TECHNIQUE IN CASE OF OVERLAPPING

\section{SCAFFOLDS}

\section{Implantation technique.}

If more than one device needs to be implanted due to lesion length, incomplete lesion coverage or edge dissections, additional devices may be implanted by carefully avoiding excessive stent overlap. An abutting technique (device-to-device) should be preferred in patients needing more than one stent.

\section{v. POST-DILATATION}

High-pressure (>16 bar) post-dilatation using non-compliant balloons should be done routinely, with nominal balloon diameter not exceeding $0.5 \mathrm{~mm}$ above the nominal diameter of the device. 


\section{vi. DEVICE FAILURE}

In cases of scaffold thrombosis, it is recommended that intravascular imaging be performed, preferably with OCT, after restoration of normal vessel flow. This may provide insight into the mechanisms underlying the scaffold thrombosis and potentially guide therapy. In most cases, implantation of a conventional DES will be the preferred strategy.

\section{Recommendations for non-clinical evaluation of bioresorbable scaffolds NON-CLINICAL TESTING}

The Task Force recommends that bench testing of the biodegradable scaffold backbone should include two components: (i) characterization of the finished product and (ii) mechanical testing.

Mechanical testing should be performed under environmental conditions that mimic physiological ones, to capture the effect of degradation on mechanical integrity over time. The duration of the accelerated fatigue testing should be determined through time of complete tissue coverage as determined by in vivo or in vitro degradation studies. Particulates testing should be performed through time of significant mass loss of the polymer.

Biocompatibility testing should be performed as recommended in the ISO standard 'Use of International Standard ISO-10993, Biological Evaluation of Medical Devices Part 1: Evaluation and Testing'. However, there may be a need to alter some of the standard tests (e.g. extraction conditions, exposure times). It is also recommended that biocompatibility testing should be performed separately on degradation products.

\section{IN VIVO TESTING}

To date, the preferable animal model for the assessment of coronary stents has been the domestic crossbred or miniature swine model or the rabbit iliac artery model ${ }^{44}$ In some situations, the sheep model may also be used. As a general rule, preclinical testing should be performed within the intended vascular territory, although there may be instances in which a switch to a different vascular location may provide valuable information about the biological behaviour of stents owing to the differential reaction to vascular injury among species and vascular territories. The ideal control should consist of a currently accepted standard of care in the specific indication for which the test product will be used clinically.

Standard measurements during histopathological assessment have been described previously. ${ }^{44}$ For the evaluation of BRS, it is important to emphasize luminal dimensions during degradation. Acute and chronic inflammation should be judged on the basis of acute and chronic inflammatory cells. Special efforts should be made to characterize the change in tissue composition during biodegradation by histopathology, focussing on both the extent and the nature of neointimal tissue especially at the remnant sites of stent struts. Correlation with intravascular imaging may be helpful in understanding changes in tissue composition. Intravascular ultrasound and optical coherence tomography are important tools in the assessment of coronary stents. Intravascular imaging is strongly recommended in a subset of animals in studies of BRS, in order that stent degradation and physiological vessel dimensions can be evaluated over time. ${ }^{45,46}$ Measurements should be adjusted using reference area, to compensate for growth during the study. ${ }^{47,48}$

Regarding duration of follow-up, we recommend it should capture all relevant biological processes pertaining to stent safety. If biodegradation of stents or stent components takes 1 year, evaluation at time points beyond 1 year is necessary to appropriately assess device safety. The addition of a late time point after bioresorption is complete may be needed to document patency of the vessel, extent of neointimal growth, and presence or absence of inflammation. Arterial drug release can be examined by direct chemical determination or by use of radioactively labelled agents. Drug concentrations in blood and major organs must also be determined, including myocardium downstream in the territory of the target artery.

Degradation products need to be clearly defined with respect to their physicochemical structure and in vivo biological behaviour. With regards to the evaluation of polymeric components, gel permeation chromatography is a suitable analytical method to assess molecular weight and polydispersity index. For the assessment of mBRS, other technologies may be applied to examine degradation products appropriately, such as chemical analysis, micro computed tomography analysis, and scanning electron microscopy with element analysis.

\section{Recommendations for clinical evaluation of bioresorbable scaffolds}

Many of the potential risks associated with BRS can be anticipated based on non-clinical evaluation. Only devices with satisfactory non-clinical assessment should undergo clinical evaluation. The Task Force suggests evaluation of current and future devices according to a standard plan; an overview is shown in Figure 4. In general, where recommendations are made with regards to the numbers of patients to be enrolled, at least $50 \%$ of these patients should be enrolled in Europe.

Initial human feasibility studies with BRS should be smallsized ( $\mathrm{N}=50-150)$, performed in selected patients, and including Intravascular ultrasound and/or optical coherence tomography imaging in addition to angiographic and clinical follow-up (see Figure 4). These studies should support the claim of efficacy and safety but also provide detailed information regarding vessel-device interactions and bioresorption process. In this regard, angiography and intracoronary imaging protocols should include assessment at baseline, at 6-12 months after device implantation, and at the time of claimed complete resorption (if longer than 12 months). Imaging can be performed at various time points in different populations in order to reduce the burden of serial invasive imaging assessment. These initial human studies may be planned as single arm, prospective, observational studies. In addition, it may be reasonable to compare the performance of investigational BRS against angiographic and clinical benchmarks derived from trials of conventional DES - using objective performance criteria in a manner similar to that detailed in the earlier report of the Task Force on coronary stents. ${ }^{1}$ Such comparison 


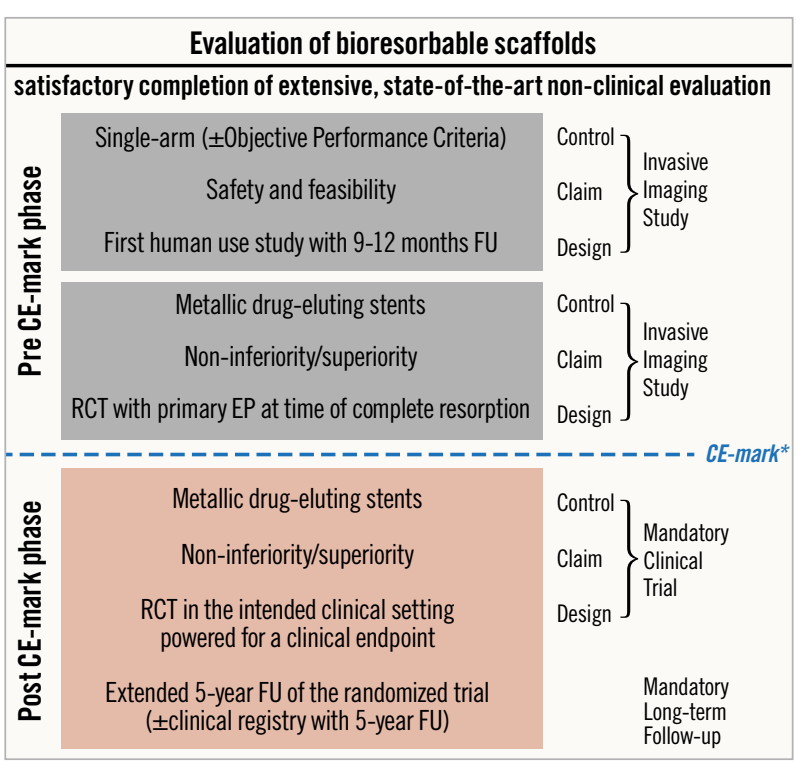

Figure 4. Task Force recommended clinical evaluation plan for bioresorbable scaffolds. *the manufacturer must submit and have approved by the notified body a plan for post-market clinical follow up in the form of a large-scale, randomized trial \pm a large-scale clinical registry. EP: end point; FU: follow-up; RCT: randomized controlled trial

may identify devices not suitable for further investigation in larger trials. Imaging surveillance protocols with non-invasive modalities such as computer tomography may be appropriate as supplementary evaluation in certain circumstances.

Subsequently a medium-sized, randomized trial $(\mathrm{N}=200-500)$ should be undertaken, powered for the detection of differences in surrogate end points in comparison with comparator devices. This should be based on angiographic surveillance at 6-12 months follow-up and include intracoronary imaging in a subgroup of patients $(\mathrm{N}=50-100)$ to compare arterial healing properties. Comparator devices should be contemporary metallic DES. It is not sufficient to compare the investigational BRS against another BRS technology at this point in time, as the performance of conventional DES makes these devices the most appropriate comparator. Surveillance angiography and intracoronary imaging during later time points (2-5 years) may evaluate delayed late loss and changes in response to the complete resorption of the BRS.

As a minimum requirement, both of these steps should be completed with satisfactory results, before any new BRS is approved and granted a CE mark. As part of this process, the manufacturer must submit and have approved by the notified body a plan for post-market clinical follow-up; in the case of BRS this plan should include the conduct of a large-scale, randomized trial, in order to assess long-term clinical efficacy and safety. Most commonly this will involve comparative efficacy testing against a benchmark DES in a trial powered for a device- or patient-specific outcome (usually requiring a sample of 1500-2500 patients) (see Figure 4). Data collection and analysis from a large-scale clinical registry including patients with broader inclusion criteria and long-term follow-up may also be requested (see Figure 4). An alternative concept would be conditional approval, with continuing market access being dependent on the conduct and satisfactory completion and reporting of a large-scale trial, but we recognize that this mechanism is not included in the new European Union Medical Device Regulation.

For the large-scale clinical trial, a non-inferiority design for the assessment of outcomes within 1 year would be acceptable, but sequential designs combining non-inferiority at 1 year followed by superiority during longer term follow-up (3-5 years) are recommended in order to evaluate the long-term effects of BRS. A deviceoriented composite end point - typically TLF - combines safety and efficacy and is commonly used in device- vs.-device comparisons of DES. Primary end point assessment should be performed at 9-12 months. Thereafter yearly follow-up out to 5 years is recommended in order to detect any late adverse event. A later time point of primary end point assessment at 2,3 , or 5 years may also be considered particularly in view of the specific bioresorption profile of any given device. The assessment of stent/scaffold thrombosis - according to established definitions for conventional metallic $\mathrm{DES}^{49}$ - should be performed at each time point of assessment.

During the conduct of trials in the post CE mark approval phase, the Task Force recommends that provision be advised for device reimbursement by payers at the price of the equivalent treatment (conventional metallic DES).

\section{Conclusion}

Bioresorbable scaffolds represent a novel technology with potential to improve the long-term outcomes of patients undergoing percutaneous coronary intervention. Presently, however, the clinical outcomes of patients treated with conventional DES are good. Accordingly, the benefit of BRS treatment over conventional stenting should be clearly demonstrated before these devices are used in routine clinical practice. Presently, five BRS have CE-mark approval for use in Europe. Only one device - the Absorb bioresorbable vascular scaffold - has published randomized clinical trial data and these data show inferior outcomes to conventional DES. For this reason, at present BRS should not be preferred to conventional DES in clinical practice. New BRS devices should undergo systematic non-clinical testing prior to evaluation in clinical studies. A clinical evaluation plan should include data from a medium-sized, randomized trial against DES powered for a surrogate end point of clinical efficacy. Manufacturers of successful devices receive CE-mark approval for use and must have an approved plan for a large-scale clinical trial with planned long-term follow-up.

\section{FUNDING}

The Task Force received its entire financial support for this report from the ESC-EAPCI.

\section{Conflict of interest}

The Task Force members completed declarations of interest forms. These forms were compiled into one file and are available online 
on the European Heart Journal website as Supplementary data file accompanying this manuscript. The Task Force received its entire financial support for drafting this report from the ESCEAPCI without any involvement from the health care industry. Notwithstanding, the ESC-EAPCI Task Force acknowledges intrinsic relations of interest as a direct result of the professional activities of its members as practitioners, researchers, and advisors. For this reason, the full report has also been reviewed and approved by members of the Regulatory Affairs Committee of the ESC, who do not have any relevant disclosures of interest.

\section{References}

1. Byrne RA, Serruys PW, Baumbach A, Escaned J, Fajadet J, James S, Joner M, Oktay S, Juni P, Kastrati A, Sianos G, Stefanini GG, Wijns W, Windecker S. Report of a European Society of Cardiology-European Association of Percutaneous Cardiovascular Interventions task force on the evaluation of coronary stents in Europe: executive summary. Eur Heart J. 2015;36:2608-20.

2. Shalaby SW, Burg KJL. Absorbable and Biodegradable Polymers (Advances in Polymeric Biomaterials). 1st ed. Boca Raton, Florida, USA: CRC Press; 2003.

3. Vert M. Bioabsorbable polymers in medicin: an overview. EuroIntervention. 2009;5:F9-F14.

4. Rep.15351 CT. Plastics. Guide for Vocabulary in the Field of Degradable and Biodegradable Polymers and Plastic Items. Standard number PD CEN/TR 15351:2006. BSI, London, UK; 2006.

5. Tada T, Byrne RA, Simunovic I, King LA, Cassese S, Joner M, Fusaro M, Schneider S, Schulz S, Ibrahim T, Ott I, Massberg S, Laugwitz KL, Kastrati A. Risk of stent thrombosis among bare-metal stents, first-generation drug-eluting stents, and second-generation drug-eluting stents: results from a registry of 18,334 patients. JACC Cardiovasc Interv. 2013;6:1267-74.

6. Bonaa KH, Mannsverk J, Wiseth R, Aaberge L, Myreng Y, Nygard O, Nilsen DW, Klow NE, Uchto M, Trovik T, Bendz B, Stavnes S, BjornerheimR, LarsenAI, SletteM, SteigenT, JakobsenOJ, Bleie O, Fossum E, Hanssen TA, Dahl-Eriksen O, Njolstad I, Rasmussen K, Wilsgaard T, Nordrehaug JE; Investigators N. Drugeluting or bare-metal stents for coronary artery disease. $N$ Engl J Med. 2016;375:1242-52.

7. Brener SJ, Kereiakes DJ, Simonton CA, Rizvi A, Newman W, Mastali K, Wang JC, Caputo R, Smith RS Jr, Ying SW, Cutlip DE, Stone GW. Everolimus-eluting stents in patients undergoing percutaneous coronary intervention: final 3-year results of the Clinical Evaluation of the XIENCE V Everolimus Eluting Coronary Stent System in the Treatment of Subjects with de Novo Native Coronary Artery Lesions trial. Am Heart J. 2013;166:1035-42.

8. Maeng M, Tilsted HH, Jensen LO, Krusell LR, Kaltoft A, Kelbæk H, Villadsen AB, Ravkilde J, Hansen KN, Christiansen EH, Aarøe J, Jensen JS, Kristensen SD, Bøtker HE, Thuesen L, Madsen M, Thayssen P, Sørensen HT, Lassen JF. Differential clinical outcomes after 1 year versus 5 years in a randomised comparison of zotarolimus-eluting and sirolimus-eluting coronary stents (the SORT OUT III study): a multicentre, open-label, randomised superiority trial. Lancet. 2014;383:2047-56.

9. Yamaji K, Raber L, Zanchin T, Spitzer E, Zanchin C, Pilgrim T, Stortecky S, Moschovitis A, Billinger M, Schonenberger C, Eberli F, Juni P, Luscher TF, Heg D, Windecker S. Ten-year clinical outcomes of first-generation drug-eluting stents: the Sirolimus-Eluting vs. Paclitaxel-Eluting Stents for Coronary Revascularization (SIRTAX) VERY LATE trial. Eur Heart J. 2016;37:3386-95.

10. Stone GW, Maehara A, Lansky AJ, de Bruyne B, Cristea E, Mintz GS, Mehran R, McPherson J, Farhat N, Marso SP, Parise H, Templin B, White R, Zhang Z, Serruys PW; Investigators P. A prospective natural-history study of coronary atherosclerosis. $N$ Engl J Med. 2011;364:226-35.

11. Haude M, Erbel R, Erne P, Verheye S, Degen H, Bose D, Vermeersch P, Wijnbergen I, Weissman N, Prati F, Waksman R, Koolen J. Safety and performance of the drug-eluting absorbable metal scaffold (DREAMS) in patients with de-novo coronary lesions: 12 month results of the prospective, multicentre, first-inman BIOSOLVE-I trial. Lancet. 2013;381:836-44.

12. Serruys PW, Ormiston J, van Geuns RJ, de Bruyne B, Dudek D, Christiansen E, Chevalier B, Smits P, McClean D, Koolen J, Windecker S, Whitbourn R, Meredith I, Wasungu L, Ediebah D, Veldhof S, Onuma Y. A polylactide bioresorbable scaffold eluting everolimus for treatment of coronary stenosis: 5-year follow-up. J Am Coll Cardiol. 2016;67:766-76.

13. Serruys PW, Chevalier B, Sotomi Y, Cequier A, Carrié D, Piek JJ, Van Boven AJ, Dominici M, Dudek D, McClean D, Helqvist S, Haude M, Reith S, de Sousa Almeida M, Campo G, Iñiguez A, Sabaté M, Windecker S, Onuma Y. Comparison of an everolimus-eluting bioresorbable scaffold with an everolimuseluting metallic stent for the treatment of coronary artery stenosis (ABSORB II): a 3 year, randomised, controlled, single-blind, multicentre clinical trial. Lancet. 2016;388:2479-91.

14. Puricel S, Arroyo D, Corpataux N, Baeriswyl G, Lehmann S, Kallinikou Z, Muller O, Allard L, Stauffer J-C, Togni M, Goy J-J, Cook S. Comparison of everolimus- and biolimus- eluting coronary stents with everolimus-eluting bioresorbable vascular scaffolds. J Am Coll Cardiol. 2015;65:791-801.

15. Kimura T, Kozuma K, Tanabe K, Nakamura S, Yamane M, Muramatsu T, Saito S, Yajima J, Hagiwara N, Mitsudo K, Popma JJ, Serruys PW, Onuma Y, Ying S, Cao S, Staehr P, Cheong WF, Kusano H, Stone GW; Investigators AJ. A randomized trial evaluating everolimus-eluting Absorb bioresorbable scaffolds vs. everolimus-eluting metallic stents in patients with coronary artery disease: ABSORB Japan. Eur Heart J. 2015;36: 3332-42.

16. Gao R, Yang Y, Han Y, Huo Y, Chen J, Yu B, Su X, Li L, Kuo HC, Ying SW, Cheong WF, Zhang Y, Su X, Xu B, Popma JJ, Stone GW; Investigators AC. Bioresorbable vascular scaffolds versus metallic stents in patients with coronary artery disease: ABSORB China Trial. J Am Coll Cardiol. 2015;66:2298-309.

17. Ellis SG, Kereiakes DJ, Metzger DC, Caputo RP, Rizik DG, Teirstein PS, Litt MR, Kini A, Kabour A, Marx SO, Popma JJ, 
McGreevy R, Zhang Z, Simonton C, Stone GW; Investigators AI. Everolimus-eluting bioresorbable scaffolds for coronary artery disease. N Engl J Med. 2015;373:1905-15.

18. Sabaté $M$, Windecker $S$, Iñiguez $A$, Okkels-Jensen $L$, Cequier A, Brugaletta S, Hofma SH, Räber L, Christiansen EH, Suttorp M, Pilgrim T, Anne van Es G, Sotomi Y, García- García HM, Onuma Y, Serruys PW. Everolimus-eluting bioresorbable stent vs. durable polymer everolimus-eluting metallic stent in patients with ST-segment elevation myocardial infarction: results of the randomized ABSORB ST-segment elevation myocardial infarctionTROFI II trial. Eur Heart J. 2016;37:229-40.

19. Wykrzykowska JJ, Kraak RP, Hofma SH, van der Schaaf RJ, Arkenbout EK, IJsselmuiden AJ, Elias J, van Dongen IM, Tijssen RY, Koch KT, Baan J Jr, Vis MM, de Winter RJ, Piek JJ, Tijssen JG, Henriques JP; Investigators A. Bioresorbable Scaffolds versus Metallic Stents in Routine PCI. N Engl J Med. 2017;376: 2319-28.

20. Puricel S. Comparison of everolimus- and biolimus-eluting coronary stents with everolimus-eluting bioresorbable vascular scaffolds: 2-year outcomes of the EVERBIO II trial. In: Presented at Transcatheter Therapeutics (TCT), San Francisco 2015.

21. Windecker S. ABSORB STEMI-TROFI II-Two-year results. In: Presented at Transcatheter Therapeutics (TCT), Washington, DC, USA, 2016.

22. Kozuma K. 3-Year Clinical and angiographic results of a randomized trial evaluating the absorb bioresorbable vascular scaffold vs. metallic drug-eluting stent in de novo native coronary artery lesions. In: Presented at euroPCR, Paris, 2017.

23. Gao R. Randomized comparison of everolimus-eluting bioresorbable vascular scaffolds vs. everolimus-eluting metallic stents in patients with coronary artery disease: 3-year clinical outcomes from ABSORB China. In: Presented at euroPCR, Paris, 2017.

24. Ellis S. Everolimus-eluting bioresorbable vascular scaffolds in patients with coronary artery disease: ABSORB III trial 2-year results. In: Presented at ACC, Washington, DC, USA, 2017.

25. Cassese S, Byrne RA, Ndrepepa G, Kufner S, Wiebe J, Repp J, Schunkert H, Fusaro M, Kimura T, Kastrati A. Everolimuseluting bioresorbable vascular scaffolds versus everolimus-eluting metallic stents: a meta-analysis of randomised controlled trials. Lancet. 2016;387:537-44.

26. Stone GW, Gao R, Kimura T, Kereiakes DJ, Ellis SG, Onuma Y, Cheong WF, Jones-McMeans J, Su X, Zhang Z, Serruys PW. 1-Year outcomes with the Absorb bioresorbable scaffold in patients with coronary artery disease: a patient-level, pooled meta-analysis. Lancet. 2016;387:1277-89.

27. Ortega-Paz L, Capodanno D, Gori T, Nef H, Latib A, Caramanno G, Di Mario C, Naber C, Lesiak M, Capranzano P, Wiebe J, Mehilli J, Araszkiewicz A, Pyxaras S, Mattesini A, Geraci S, Naganuma T, Colombo A, Münzel T, Sabaté M, Tamburino C, Brugaletta S. Predilation, sizing and post-dilation scoring in patients undergoing everolimus-eluting bioresorbable scaffold implantation for prediction of cardiac adverse events: development and internal validation of the PSP score. EuroIntervention. 2017;12:2110-7.

28. Puricel S, Cuculi F, Weissner M, Schmermund A, Jamshidi P, Nyffenegger T, Binder H, Eggebrecht H, Munzel T, Cook S, Gori T. Bioresorbable coronary scaffold thrombosis: multicenter comprehensive analysis of clinical presentation, mechanisms, and predictors. J Am Coll Cardiol. 2016;67:921-31.

29. Cassese S, Byrne RA, Jüni P, Wykrzykowska J, Puricel S, Ndrepepa G, SchunkertH, Fusaro M, Cook S, Kimura T, Henriques JP, Serruys PW, Windecker S, Kastrati A. Mid- term clinical outcomes with everolimus-eluting bioresorbable scaffolds versus everolimuseluting metallic stents for percutaneous coronary interventions: a meta-analysis of randomized trials. EuroIntervention. 2017; pii: EIJ-D-17-00492. doi: 10.4244EIJ-D-17-00492.

30. Abizaid A, Costa JR Jr, Bartorelli AL, Whitbourn R, van Geuns RJ, Chevalier B, Patel T, Seth A, Stuteville M, Dorange C, Cheong WF, Sudhir K, Serruys PW. The ABSORB EXTEND study: preliminary report of the twelve-month clinical outcomes in the first 512 patients enrolled. EuroIntervention. 2014;10: 1396-401.

31. Brugaletta S, Gori T, Low AF, Tousek P, Pinar E, GomezLara J, Scalone G, Schulz E, Chan MY, Kocka V, Hurtado J, Gomez-Hospital JA, Münzel T, Lee C-H, Cequier A, Valdés M, Widimsky P, Serruys PW, Sabaté M. Absorb bioresorbable vascular scaffold versus everolimus-eluting metallic stent in ST-segment elevation myocardial infarction: 1-year results of a propensity score matching comparison: the BVS-EXAMINATION Study (bioresorbable vascular scaffold-a clinical evaluation of everolimus eluting coronary stents in the treatment of patients with ST-segment elevation myocardial infarction). JACC Cardiovasc Interv. 2015;8: 189-97.

32. Capodanno D, Gori T, Nef H, Latib A, Mehilli J, Lesiak M, Caramanno G, Naber C, Di Mario C, Colombo A, Capranzano P, Wiebe J, Araszkiewicz A, Geraci S, Pyxaras S, Mattesini A, Naganuma T, Munzel T, Tamburino C. Percutaneous coronary intervention with everolimus-eluting bioresorbable vascular scaffolds in routine clinical practice: early and midterm outcomes from the European multicentre GHOST-EU registry. EuroIntervention. 2015;10:1144-53.

33. Hoppmann P, Kufner S, Cassese S, Wiebe J, Schneider S, Pinieck S, Scheler L, Bernlochner I, Joner M, Schunkert H, Laugwitz KL, Kastrati A, Byrne RA. Angiographic and clinical outcomes of patients treated with everolimus-eluting bioresorbable stents in routine clinical practice: results of the ISAR-ABSORB registry. Catheter Cardiovasc Interv. 2016;87: 822-9.

34. Onuma Y, Sotomi Y, Shiomi H, Ozaki Y, Namiki A, Yasuda S, Ueno T, Ando K, Furuya J, Igarashi K, Kozuma K, Tanabe K, Kusano H, Rapoza R, Popma JJ, Stone GW, Simonton C, Serruys PW, Kimura T. Two-year clinical, angiographic, and serial optical coherence tomographic follow-up after implantation of an everolimus-eluting bioresorbable scaffold and an everolimuseluting metallic stent: insights from the randomised ABSORB Japan trial. EuroIntervention. 2016;12:1090-101. 
35. Raber L, Brugaletta S, Yamaji K, O'Sullivan CJ, Otsuki S, Koppara T, Taniwaki M, Onuma Y, Freixa X, Eberli FR, Serruys PW, Joner M, Sabate M, Windecker S. Very late scaffold thrombosis: intracoronary imaging and histopathological and spectroscopic findings. J Am Coll Cardiol. 2015;66:1901-14.

36. Sotomi Y, Suwannasom P, Serruys PW, Onuma Y. Possible mechanical causes of scaffold thrombosis: insights from case reports with intracoronary imaging. EuroIntervention. 2017;12: 1747-56.

37. Abizaid A, Costa RA, Schofer J, Ormiston J, Maeng M, Witzenbichler B, Botelho RV, Costa JR Jr, Chamie D, Abizaid AS, Castro JP, Morrison L, Toyloy S, Bhat V, Yan J, Verheye S. Serial multimodality imaging and 2-year clinical outcomes of the novel desolve novolimus-eluting bioresorbable coronary scaffold system for the treatment of single de novo coronary lesions. JACC Cardiovasc Interv. 2016;9:565-74.

38. Wiebe J, Dorr O, Ilstad H, Husser O, Liebetrau C, Boeder N, Bauer T, Mollmann H, Kastrati A, Hamm CW, Nef HM. Everolimus- Versus Novolimus-Eluting Bioresorbable Scaffolds for the Treatment of Coronary Artery Disease: A Matched Comparison. JACC Cardiovasc Interv. 2017;10:477-85.

39. Haude $M$, Ince $H$, Abizaid $A$, Toelg R, Lemos PA, von Birgelen C, Christiansen EH, Wijns W, Neumann FJ, Kaiser C, Eeckhout E, Lim ST, Escaned J, Onuma Y, Garcia-Garcia HM, Waksman R. Sustained safety and performance of the second-generation drug-eluting absorbable metal scaffold in patients with de novo coronary lesions: 12-month clinical results and angiographic findings of the BIOSOLVE-II first-in-man trial. Eur Heart $J$. 2016;37:2701-9.

40. Haude M, Ince H, Abizaid A, Toelg R, Lemos PA, von Birgelen C, Christiansen EH, Wijns W, Neumann FJ, Kaiser C, Eeckhout E, Lim ST, Escaned J, Garcia-Garcia HM, Waksman R. Safety and performance of the second-generation drug-eluting absorbable metal scaffold in patients with de-novo coronary artery lesions (BIOSOLVE-II): 6 month results of a prospective, multicentre, non-randomised, first-in-man trial. Lancet. 2016;387:31-9.

41. Windecker S, Kolh P, Alfonso F, Collet JP, Cremer J, Falk V, Filippatos G, Hamm C, Head SJ, Juni P, Kappetein AP, Kastrati A, Knuuti J, Landmesser U, Laufer G, Neumann FJ, Richter DJ, Schauerte P, Sousa Uva M, Stefanini GG, Taggart DP, Torracca L, Valgimigli M, Wijns W, Witkowski A; Authors/Task Force Members. 2014 ESC/EACTS Guidelines on myocardial revascularization: the Task Force on Myocardial Revascularization of the European Society of Cardiology (ESC) and the European Association for Cardio-Thoracic Surgery (EACTS) Developed with the special contribution of the European Association of Percutaneous Cardiovascular Interventions (EAPCI). Eur Heart J. 2014;35:2541-619.

42. Collet C, Asano T, Miyazaki Y, Tenekecioglu E, Katagiri Y, Sotomi Y, Cavalcante R, de Winter RJ, Kimura T, Gao R, Puricel S,
Cook S, Capodanno D, Onuma Y, Serruys PW. Late thrombotic events after bioresorbable scaffold implantation: a systematic review and meta-analysis of randomized clinical trials. Eur Heart J. 2017; doi 10.1093/eurheartj/ehx155.

43. Felix CM, Vlachojannis GJ, Ij AJJ, Fam JM, Smits PC, Lansink WJ, Diletti R, Zijlstra F, Regar ES, Boersma E, Onuma Y, van Geuns RJM. Potentially increased incidence of scaffold thrombosis in patients treated with Absorb BVS who terminated DAPT before 18 months. EuroIntervention. 2017;13:e177-e184.

44. Schwartz RS, Edelman ER, Carter A, Chronos N, Rogers C, Robinson KA, Waksman R, Weinberger J, Wilensky RL, Jensen DN, Zuckerman BD, Virmani R; Consensus C. Drug-eluting stents in preclinical studies: recommended evaluation from a consensus group. Circulation. 2002;106:1867-73.

45. Onuma Y, Serruys PW, Perkins LE, Okamura T, Gonzalo N, Garcia-Garcia HM, Regar E, Kamberi M, Powers JC, Rapoza R, van Beusekom H, van der Giessen W, Virmani R. Intracoronary optical coherence tomography and histology at 1 month and 2, 3, and 4 years after implantation of everolimus-eluting bioresorbable vascular scaffolds in a porcine coronary artery model: an attempt to decipher the human optical coherence tomography images in the ABSORB trial. Circulation. 2010;122:2288-300.

46. Campos CM, Ishibashi Y, Eggermont J, Nakatani S, Cho YK, Dijkstra J, Reiber JH, Sheehy A, Lane J, Kamberi M, Rapoza R, Perkins L, Garcia-Garcia HM, Onuma Y, Serruys PW. Echogenicity as a surrogate for bioresorbable everolimus-eluting scaffold degradation: analysis at 1-, 3-, 6-, 12- 18, 24-, 30-, 36- and 42-month followup in a porcine model. Int $J$ Cardiovasc Imaging. 2015;31:471-82.

47. Lane JP, Perkins LE, Sheehy AJ, Pacheco EJ, Frie MP, Lambert BJ, Rapoza RJ, Virmani R. Lumen gain and restoration of pulsatility after implantation of a bioresorbable vascular scaffold in porcine coronary arteries. JACC Cardiovasc Interv. 2014;7:688-95. 48. Strandberg E, Zeltinger J, Schulz DG, Kaluza GL. Late positive remodeling and late lumen gain contribute to vascular restoration by a non-drug eluting bioresorbable scaffold: a four-year intravascular ultrasound study in normal porcine coronary arteries. Circ Cardiovasc Interv. 2012;5:39-46.

49. Cutlip DE, Windecker S, Mehran R, Boam A, Cohen DJ, van Es GA, Steg PG, Morel MA, Mauri L, Vranckx P, McFadden E, Lansky A, Hamon M, Krucoff MW, Serruys PW. Clinical end points in coronary stent trials: a case for standardized definitions. Circulation. 2007;115:2344-51.

\section{Supplementary data}

Report of the ESC-EAPCI Task Force on the evaluation and use of bioresorbable scaffolds for percutaneous coronary intervention.

\footnotetext{
The supplementary data are published online at:

http://www.pcronline.com/

eurointervention/128th_issue/253
} 